TITLE:

\title{
Failure Case Study of Tieback Wall in Urban Area, Korea
}

$\operatorname{AUTHOR}(S)$ :

Jeong, Sang-Seom; Kim, Young-Ho; Kim, MyoungMo

\section{CITATION:}

Jeong, Sang-Seom ... [et al]. Failure Case Study of Tieback Wall in Urban Area, Korea. Proceeding of TC302 Symposium Osaka 2011 : International Symposium on Backwards Problem in Geotechnical Engineering and Monitoring of GeoConstruction 2011: 19 ...

ISSUE DATE:

2011

URL:

http://hdl.handle.net/2433/173849

RIGHT: 


\title{
Failure Case Study of Tieback Wall in Urban Area, Korea
}

\author{
S. S. Jeong \& Y. H. Kim \\ Dep. of Civil Eng, Yonsei University, Seoul, Korea
}

M. M. Kim (corresponding author)

Dep. of Civil and Env. Eng., Seoul National Univ., Seoul, Korea

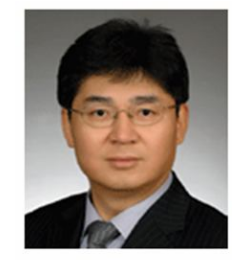

Jeong, Sang-Seom,

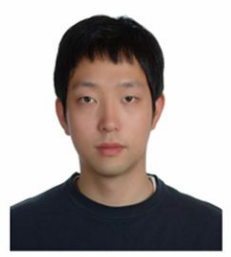

Kim, Young-Ho,

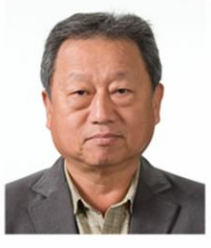

Kim, Myoung-Mo

ABSTRACT: In this study, a numerical analysis was performed to reproduce the sequential behavior of an anchored retaining structure in an urban area. The numerical analysis was verified through comparisons between the prediction and a field failure case. The emphasis was placed on the wall behavior and the location of the sliding surface based on the elasto-plastic method and the shear strength reduction FEM method. Through the comparison study, it is found that coupled analysis using the shear strength reduction method can be effectively used to perform the back calculation analysis to find a critical surface in the anchored wall structures, whereas uncoupled analysis by the elasto-plastic method can be applicable to the preliminary design of a retaining wall with a suitable safety factor.

\section{INTRODUCTION}

South Korea suffers from serious lack of land space due to its high population of about 47 million people on a little less than $100,000 \mathrm{~km}^{2}$ of land and the fact that $75 \%$ of the land space is mountainous. Since 1980, a number of huge excavation projects such as underground space for constructing power stations, subways, high-speed railways, and many lifeline constructions have been performed in urban areas. The retaining structures such as the slurry wall, C.I.P wall and H-pile are frequently used in those areas as temporary excavation proceeds.

The analysis technique for analyzing the sequential behavior of anchored retaining wall has been developed for decades (Haliburton, 1968; Clough, 1971; Clough and Tsui, 1974; Briaud and Kim, 1998; Jeong and Seo, 2004). Although these methods make slightly different assumptions, they can generally be classified into two main groups: (1)elasto-plastic method, (2)finite-element method (shear strength reduction).

The objective of this study is to suggest the conceptual methodology of anchored retaining wall design by considering the coupling effect between soil and structure. Comparisons are made between the soil-wall behavior computed by elasto-plastic, and finite-element analysis which consider the mechanism of shear strength reduction using the material properties of real failure case.

\section{ANALYTICAL METHODS FOR ANCHORED RETAINING WALL}

\subsection{Elasto-plastic method}

The elasto-plastic method is based on beam-column theory, which has been studied for many applications in engineering practice. Governing equation for the horizontal beam modeling of anchored retaining wall is as follows:

$$
E I \frac{d^{4} y}{d x^{4}}+\frac{A \cdot E^{\prime}}{L} \cdot x=p_{i}-k_{s} \cdot x
$$

where, $\mathrm{E}$ is the elastic modulus of retaining wall; $\mathrm{I}$ is the inertia moments of retaining wall; $A$ is the area of bore hole; E' is the elastic modulus of bore hole; $\mathrm{L}$ is the length of bore hole; $p_{i}$ is the initial earth pressure; $\mathrm{k}_{\mathrm{s}}$ is the horizontal subgrade reaction; $\mathrm{x}$ is the depth; $\mathrm{y}$ is the horizontal wall deflection. This method is developed for rigid beam with infinite length and is assumed that the soil is rigid and perfectly plastic. Thus, this method may not represent the behavior of actual wall in the field: this method does not take into account the actual behavior of finite flexible beams, soil arching and soft soil, etc. (Hassiotis, 1997; Cai et. al., 2000) Schematic drawings of the elasto-plastic modeling for a retaining wall is shown in Figure 1. 


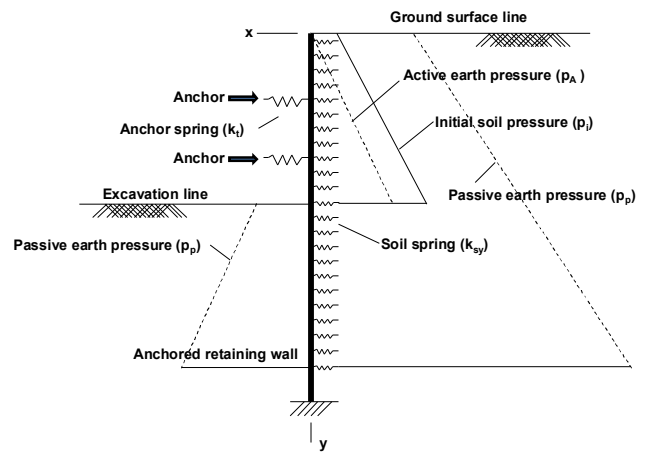

Fig. 1 Schematic drawing of elasto-plastic modeling

\subsection{Finite element method (shear strength reduction)}

The finite element method has been used to investigate the soil-structure system, which is analyzed as a continuous elastic or elasto-plastic medium using finite element formulations. This method provides coupled solutions in which the wall and slope response are considered simultaneously.

For retaining wall, the factor of safety $F$ is traditionally defined as the ratio of the actual soil shear strength to the minimum shear strength required to prevent failure. The 'shear strength reduction technique' was used as early as 1975 by Zienkiewicz et al., and has been applied by Naylor (1981), Donald and Giam (1988), and Won (2005), etc. In the shear strength reduction FEM method, the shear strength of soil is reduced and the factor of safety is recalculated until collapse occurs.

To calculate the factor of safety of a retaining wall structure defined in the shear strength reduction technique, a series of stability analyses are performed with the reduced shear strength parameters $\mathrm{c}^{\prime}{ }_{\text {trial }}$ and $\varphi$ 'trial (Figure 2)defined as follows :

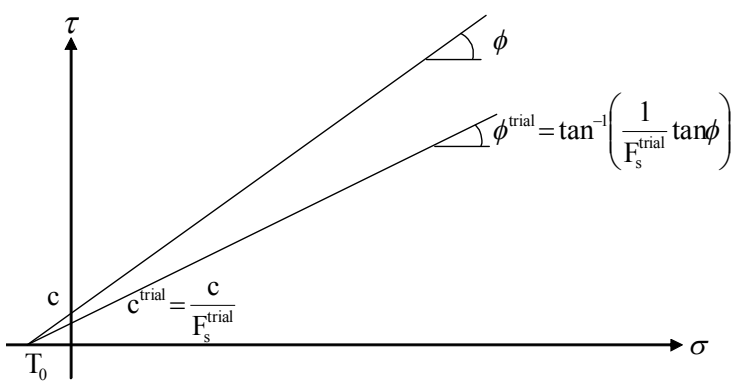

Fig. 2. Relationship between the actual strength and the strength reduced by a trial factor of safety.

$$
\begin{aligned}
& c_{\text {trial }}^{\prime}=\frac{1}{F^{\text {trial }}} c^{\prime} \\
& \phi_{\text {trial }}^{\prime}=\arctan \left(\frac{1}{F^{\text {trial }}} \tan \phi^{\prime}\right)
\end{aligned}
$$

where $c^{\prime}, \varphi^{\prime}$ are the real shear strength parameters and $F_{\text {trial }}$ is a trial factor of safety. Usually, initial $F_{\text {trial }}$ is set to be sufficiently small so as to guarantee that the system is stable. Then the value of $F_{\text {trial }}$ is increased by $\mathrm{F}_{\text {inc }}$ values until the retaining wall fails.

\subsection{Failure surface}

A typical failure surface used in the elasto-plastic analysis is shown in Figure 3. The failure surface defined in the shear strength reduction FEM as the curve which passes the elements having maximum shear strain ratio(Figure 4).

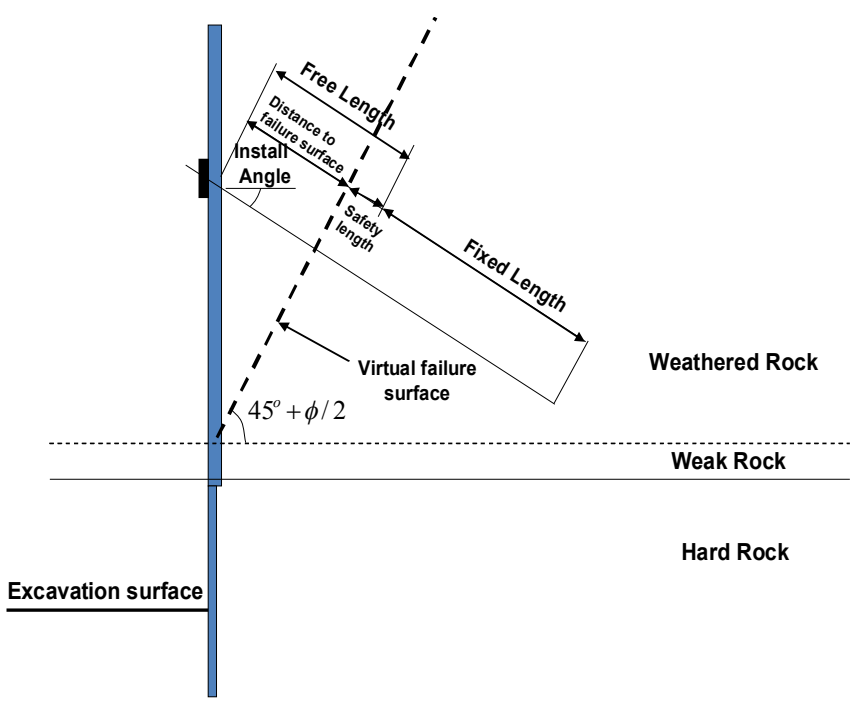

Fig. 3 Failure surface in Rankine's active zone

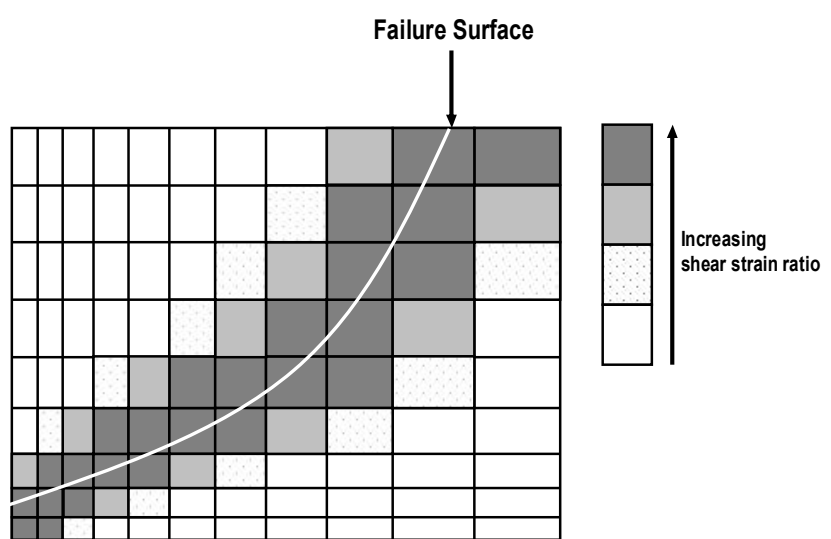

Fig. 4 Failure surface in finite element method

\section{MODELING OF ANCHORED RETAINING WALL}

\subsection{An example case of wall failure}

In this study, an analysis section was adopted from a construction field in urban area where the failure accident took place. As shown in Figure 5, the retaining wall consisted of $18.3 \mathrm{~m}$ CIP (cast-in place pile) wall plus $21.7 \mathrm{~m} \mathrm{H}$-pile, and was braced with nine earth anchors (various free length) and thirteen 
rock bolts downwards. Based on the in-situ and laboratory soil tests, soil profile was constructed as being composed of medium to dense sand in the upper $17.5 \mathrm{~m}$ underlain by weathered rock and weak to hard rock. Specially, the fracture zone was noted in the hard rock layer at depths below $30.4 \mathrm{~m}$. Sequential excavation proceeded until the wall failure occurred (38m excavation). Based on the construction sequence, the excavation stage and the water table location are summarized in Table 1.

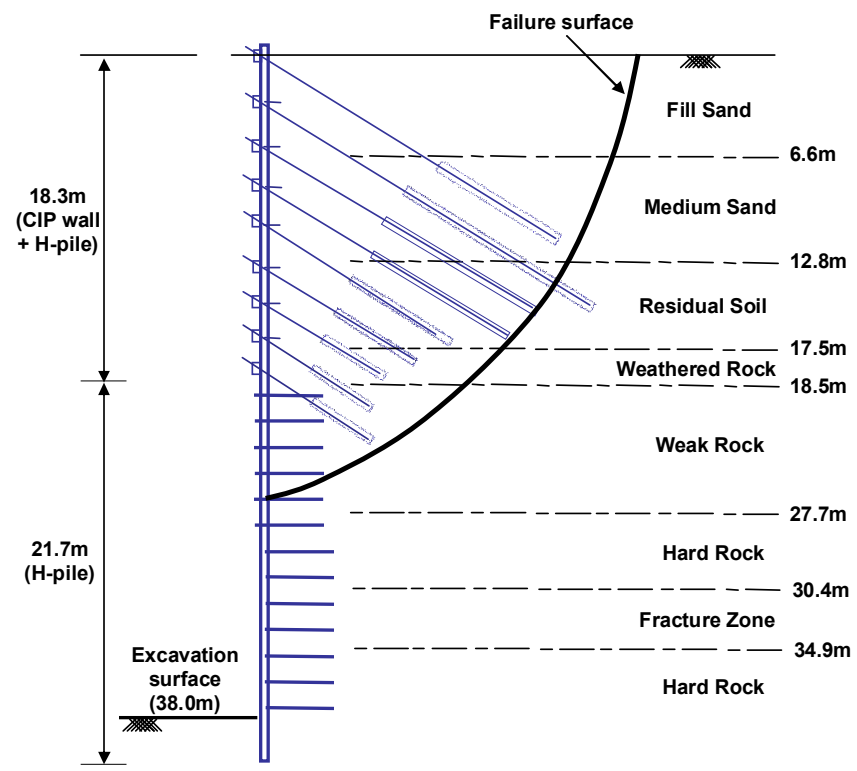

Fig. 5 Analysis section of anchored retaining wall

\subsection{Numerical simulation}

To obtain detailed information on the behavior of the anchored retaining wall, a series of numerical analyses were performed for the site of failure. The response of an anchored retaining wall was analyzed in parallel by the elasto-plastic method and by the 2D nonlinear finite-element method.

First, the elasto-plastic analysis (SUNNEX, 2002) was executed which is based on an iterative and incremental procedure to take into account the changes of the earth pressures and wall displacements at each construction stages. Second, the Finite Element Method modeled the site under the plane strain condition. The finite-element mesh for a typical case is shown in Figure 6. The mesh consisted of 2D six-noded solid triangular elements and was assumed to be resting on a rigid layer. The wall element remained elastic at all times, while the surrounding soil was idealized as a Mohr-Coulomb elasto-plastic material. The interface element was composed of 1D quadratic three-node elements. The Coulomb's frictional criterion was used to distinguish between elastic behavior, where small displacements can occur within the interface, and plastic interface behavior (slip). The interface properties were taken from the associated soil properties surrounding the wall using the strength reduction factor $\left(\mathrm{R}_{\mathrm{i}}\right)$ as follows:

$$
c_{i}=R_{i} \times c_{\text {soil }}, \quad \tan \phi_{i}=R_{i} \times \tan \phi_{\text {soil }}
$$

where $c_{i}$ and $\phi_{i}$ are the cohesion and friction angle of the interface, $c_{\text {soil }}$ and $\varphi_{\text {soil }}$ are the cohesion and friction angle of the soil mass. This model was selected in the element library of PLAXIS (2005), the commercial finite element package used for this work.

Table 2 shows the anchor forces and their dimensions, and Table 3 shows material properties used in numerical analyses.

Table 1. Construction stages for the failure site

\begin{tabular}{|c|c|c|c|c|c|}
\hline $\begin{array}{l}\text { Excavation } \\
\text { Stage }\end{array}$ & \multicolumn{2}{|c|}{ Construction } & $\begin{array}{c}\text { Excavation } \\
(\mathrm{m})\end{array}$ & $\begin{array}{l}\text { Water Table } \\
\text { (m) }\end{array}$ & Remark \\
\hline- & \multicolumn{2}{|c|}{$\begin{array}{l}\text { Retaining wall } \\
\text { \& H-pile }\end{array}$} & - & 11.90 & - \\
\hline $1^{\text {st }}$ & \multicolumn{2}{|c|}{-} & 2.04 & 11.90 & \multirow{3}{*}{$\begin{array}{l}\text { Fill } \\
\text { Sand }\end{array}$} \\
\hline $2^{\text {nd }}$ & \multirow{8}{*}{$\begin{array}{c}\text { Anchor } \\
\text { No. }\end{array}$} & No.1 & 4.58 & 11.90 & \\
\hline $3^{\text {rd }}$ & & No. 2 & 7.01 & 11.90 & \\
\hline $4^{\text {th }}$ & & No.3 & 9.30 & 11.90 & \multirow{4}{*}{$\begin{array}{l}\text { Medium } \\
\text { Sand }\end{array}$} \\
\hline $5^{\text {th }}$ & & No.4 & 11.60 & 11.90 & \\
\hline $6^{\text {th }}$ & & No. 5 & 13.84 & 11.90 & \\
\hline $7^{\text {th }}$ & & No.6 & 15.91 & 13.91 & \\
\hline $8^{\text {th }}$ & & No.7 & 17.46 & 15.46 & $\begin{array}{c}\text { Residual } \\
\text { Soil }\end{array}$ \\
\hline $9^{\text {th }}$ & & No.8, 9 & 18.59 & 16.59 & \multirow{2}{*}{$\begin{array}{l}\text { Weathered } \\
\text { Rock }\end{array}$} \\
\hline $10^{\text {th }}$ & \multirow{13}{*}{$\begin{array}{c}\text { Rock- } \\
\text { Bolt } \\
\text { No. }\end{array}$} & No.1 & 20.66 & 18.66 & \\
\hline $11^{\text {th }}$ & & No. 2 & 22.16 & 20.16 & \multirow{6}{*}{$\begin{array}{l}\text { Weak } \\
\text { Rock }\end{array}$} \\
\hline $12^{\text {th }}$ & & No. 3 & 23.66 & 21.66 & \\
\hline $13^{\text {th }}$ & & No.4 & 25.16 & 23.16 & \\
\hline $14^{\text {th }}$ & & No. 5 & 26.66 & 24.66 & \\
\hline $15^{\text {th }}$ & & No.6 & 28.16 & 26.16 & \\
\hline $16^{\text {th }}$ & & No.7 & 29.66 & 27.66 & \\
\hline $17^{\text {th }}$ & & No. 8 & 31.16 & 29.16 & \multirow{2}{*}{$\begin{array}{l}\text { Hard } \\
\text { Rock }\end{array}$} \\
\hline $18^{\mathrm{h}}$ & & No.9 & 32.66 & 30.66 & \\
\hline $19^{\text {th }}$ & & No.10 & 34.16 & 32.16 & \multirow{2}{*}{$\begin{array}{c}\text { Fracture } \\
\text { Zone }\end{array}$} \\
\hline $20^{\text {th }}$ & & No.11 & 35.66 & 33.66 & \\
\hline 21th & & No.12 & 37.16 & 35.16 & \multirow{2}{*}{$\begin{array}{l}\text { Hard } \\
\text { Rock }\end{array}$} \\
\hline 22 th & & No.13 & 38.00 & 36.00 & \\
\hline
\end{tabular}




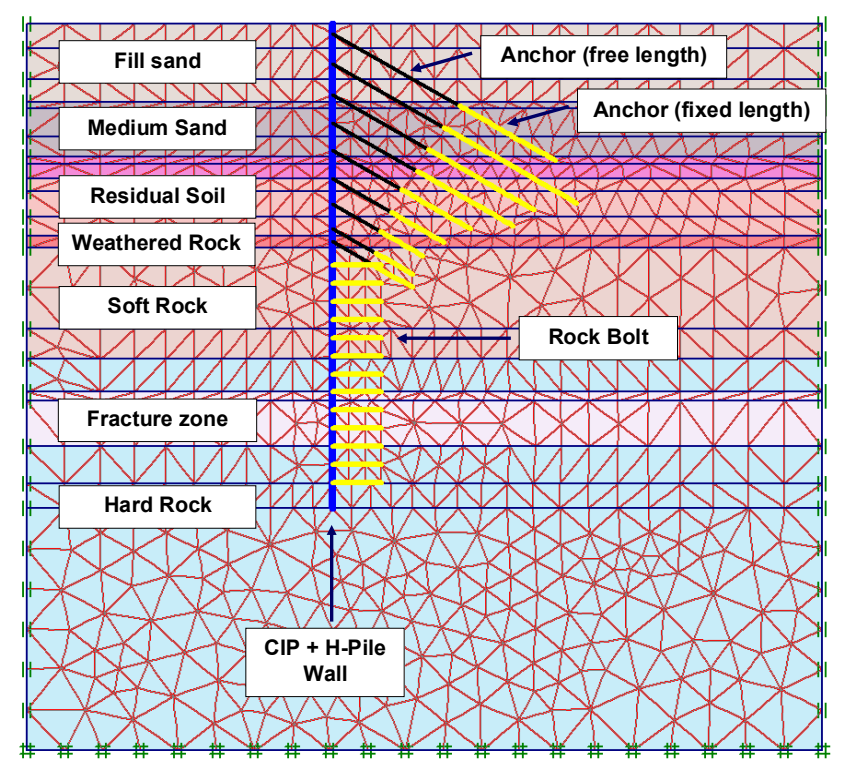

Fig. 6. Element mesh and boundary conditions

\section{COMPARISON OF ELASTO-PLASTIC METHOD WITH FINITE ELEMENT METHOD}

\subsection{Lateral deflection of retaining wall}

Figure 7 shows the predicted and measured lateral deflection profiles from initial to final construction stages. The measured deflection profiles were obtained from field inclinometer data.

Table is ssen in the figure that the finite element method predicts the wall deffection refatively well

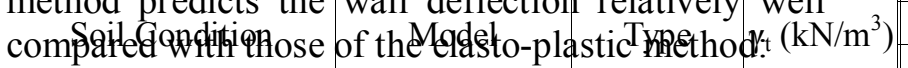

\begin{tabular}{|c|c|c|c|c|c|c|c|c|c|}
\hline \multirow{2}{*}{\multicolumn{4}{|c|}{$\begin{array}{l}\text { 4. COMPARISON OF ELASTO-PLASTIC } \\
\text { METHOD WITH FINITE ELEMENT METHOD }\end{array}$}} & \\
\hline & & & & \multirow{2}{*}{$\begin{array}{c}\text { Earth } \\
\text { Anchor } \\
\text { No.1 }\end{array}$} & $\begin{array}{l}\text { Fixed } \\
\text { Length } \\
\quad(\mathrm{m})\end{array}$ & \multirow{2}{*}{$\begin{array}{c}\text { Free } \\
\text { Length } \\
(\mathrm{m})\end{array}$} & \multicolumn{2}{|c|}{$\begin{array}{l}\text { Number } \\
\text { of } \\
\text { Steel Wire }\end{array}$} & \multirow{2}{*}{$\begin{array}{c}\text { Anchor } \\
\text { Force } \\
(\mathrm{kN})\end{array}$} \\
\hline \multirow{7}{*}{\multicolumn{4}{|c|}{$\begin{array}{l}\text { 4.1. Lateral deflection of retaining wall } \\
\text { Figure } 7 \text { shows the predicted and measured lateral } \\
\text { deflection profiles from initial to final construction } \\
\text { stages. The measured deflection profiles were } \\
\text { obtained from field inclinometer data. } \\
\text { It is seen in the figure that the finite element } \\
\text { methe 3. Material propertres and geometries predicts the wall deflection retatively well }\end{array}$}} & & 12 & & \multicolumn{2}{|l|}{3} & \\
\hline & & & & No. 2 & 10.5 & 12.5 & \multicolumn{2}{|l|}{3} & 233 \\
\hline & & & & No.3 & 9 & 10 & \multicolumn{2}{|l|}{3} & 255.6 \\
\hline & & & & No.4 & 8 & 9 & \multicolumn{2}{|l|}{3} & 277.8 \\
\hline & & & & No.5 & 6.5 & 6.5 & \multicolumn{2}{|l|}{4} & 346.4 \\
\hline & & & & No.6 & 5.5 & 5 & \multicolumn{2}{|l|}{4} & 352 \\
\hline & & & & c $\left(\mathrm{N} \mathrm{No} \cdot \mathrm{m}^{2}\right)$ & $\phi 4.5 \mathrm{deg})$ & \multicolumn{3}{|c|}{${ }^{4} \mathrm{E}\left(\mathrm{kN} / \mathrm{m}^{2}\right)^{4}$} & $\begin{array}{l}369 R_{i} \\
3752\end{array}$ \\
\hline Fill Sand & M.C & Drained & 18 & N8.9 & $4^{26}$ & \multicolumn{2}{|c|}{$3.5^{10,000} 4$} & 0.3 & 375.2 \\
\hline Medium Sand & M.C & Drained & 18 & 5 & 31 & \multicolumn{2}{|c|}{20,000} & 0.3 & - \\
\hline Residual Soil & M.C & Drained & 19 & 10 & 33 & \multicolumn{2}{|c|}{40,000} & 0.3 & - \\
\hline Weathered Rock & M.C & Drained & 20 & 30 & 35 & \multicolumn{2}{|c|}{151,900} & 0.3 & - \\
\hline Soft Rock & M.C & Drained & 21 & 120 & 42 & \multicolumn{2}{|c|}{381,600} & 0.25 & - \\
\hline Facture Zone & M.C & Drained & 20 & 71 & 26 & \multicolumn{2}{|c|}{266,750} & 0.3 & - \\
\hline Hard Rock & M.C & Drained & 23 & 1074 & 63 & \multicolumn{2}{|c|}{$5,000,000$} & 0.2 & - \\
\hline CIP wall & Beam & non-porous & 50 & - & - & $8.2 \mathrm{x}$ & 107 & 0.2 & 0.8 \\
\hline H-pile & Beam & non-porous & 50 & - & - & $5.6 x$ & 107 & 0.2 & 0.6 \\
\hline Reinforcements & Model & Horizontal & $\operatorname{acing}(\mathrm{m})$ & Size $(n$ & & ngle (deg) & $\mathrm{E} \cdot \mathrm{A}($ & & $v$ \\
\hline Earth anchor (No.1 3) & Node-to-Node & & & $\Phi 12.7$ & & $30^{\circ}$ & 19,7 & & 0.2 \\
\hline Earth anchor (No.4) & \& & & & $\Phi 12.7$ & & $30^{\circ}$ & 32,9 & & 0.2 \\
\hline Earth anchor(No.5 9) & Geogrid & & & $\Phi 12.7$ & & $30^{\circ}$ & 236,2 & & 0.2 \\
\hline Rock Bolt (No.1 13) & Geogrid & & & $\Phi 25$ & & $0^{\circ}$ & 272, & & 0.2 \\
\hline
\end{tabular}

\subsection{Bending moment and earth pressure}

Figure 8 and Figure 9 show the predicted bending moments and earth pressures mobilized in the retaining wall. The overall distributions are alike for the finite element method and the elasto-plastic method until the middle construction stage. As the construction stage proceeds to the final stage, the distributions become dissimilar each other especially at the lower part of the excavation

\subsection{Failure surface}

Figure 10 compares the measured failure surface with the failure surface predicted by the FEM after the final excavation stage. From this comparison, it is confirmed that the shear strength reduction method simulates well the field failure surface. In Figure 11, the possible failure surfaces are shown for the middle stages of excavation.

Table 2. Anchor forces and properties 


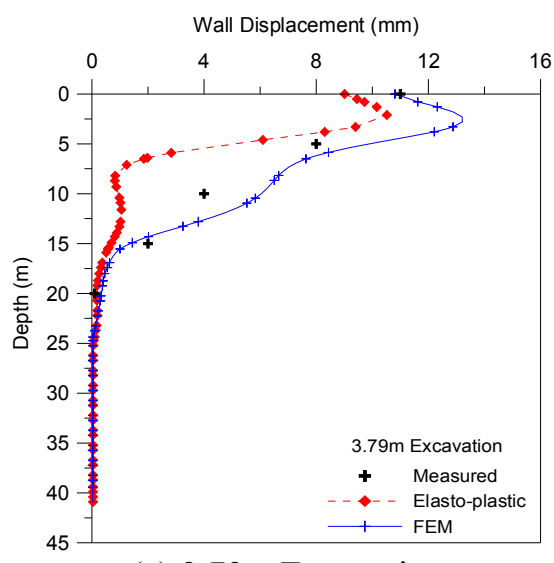

(a) $3.79 \mathrm{~m}$ Excavation

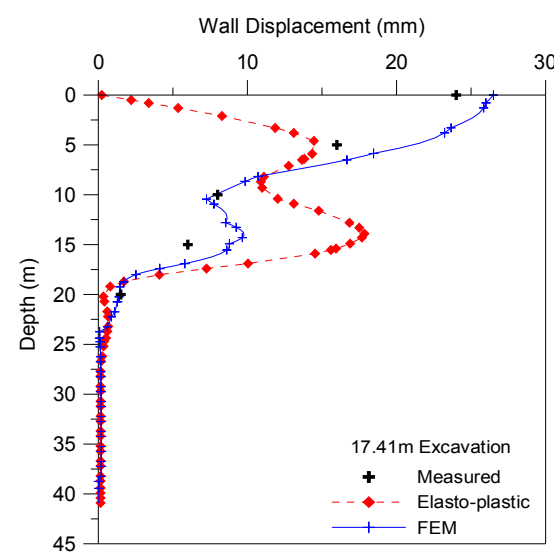

(b) $17.41 \mathrm{~m}$ Excavation

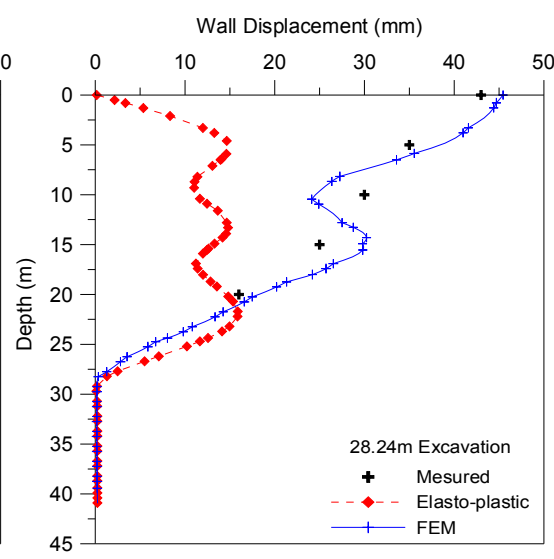

(c) $28.24 \mathrm{~m}$ Excavation

Fig. 7 Measured and Predicted lateral deflection of anchored retaining wall

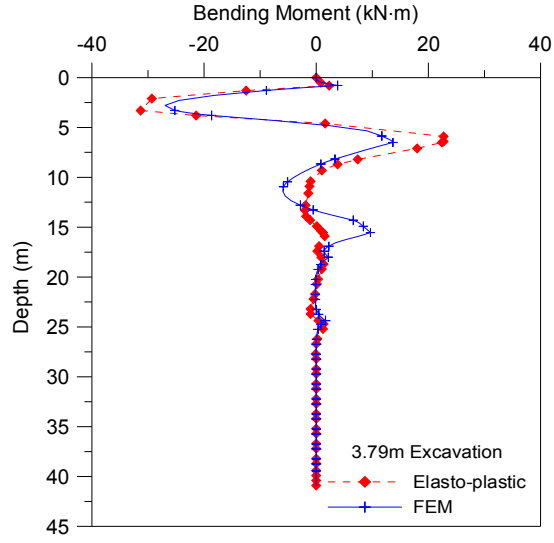

(a) $3.79 \mathrm{~m}$ Excavation

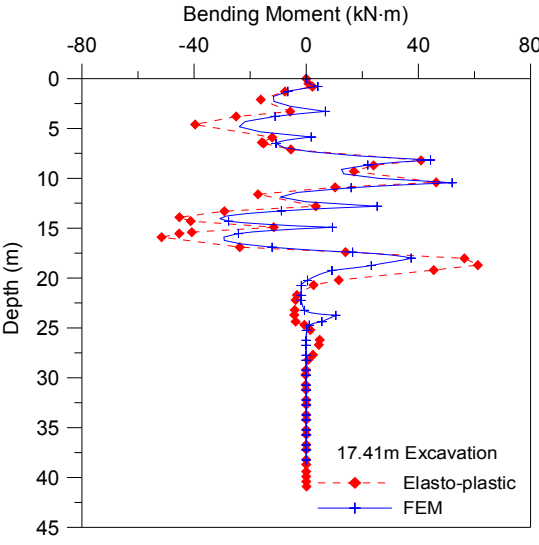

(b) $17.41 \mathrm{~m}$ Excavation

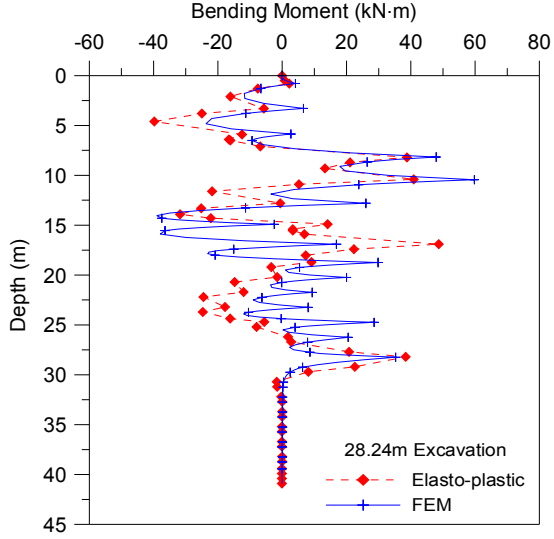

(c) $28.24 \mathrm{~m}$ Excavation

Fig. 8 Bending moment distribution of anchored retaining wall

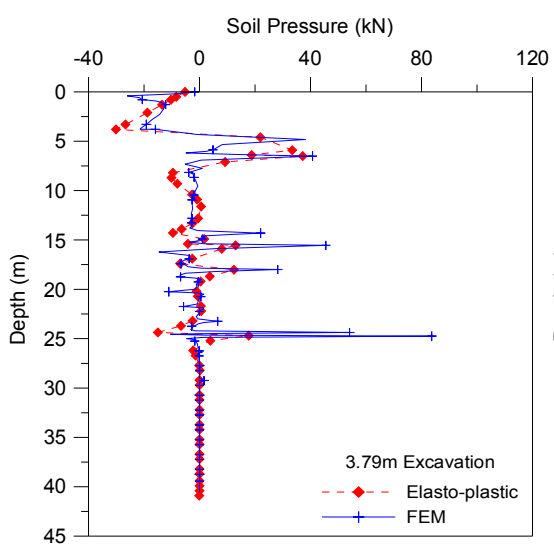

(a) $3.79 \mathrm{~m}$ Excavation

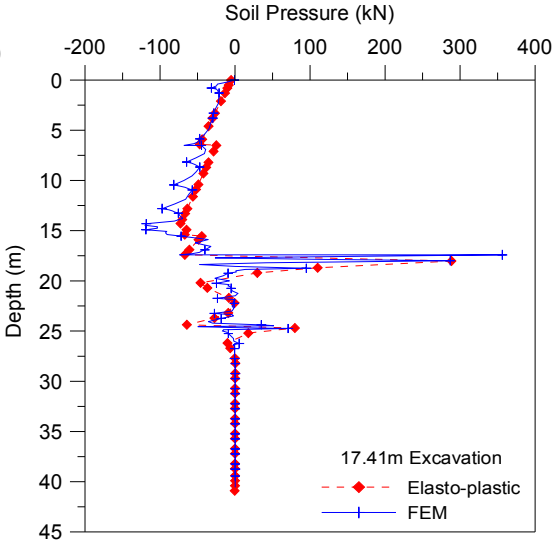

(b) $17.41 \mathrm{~m}$ Excavation

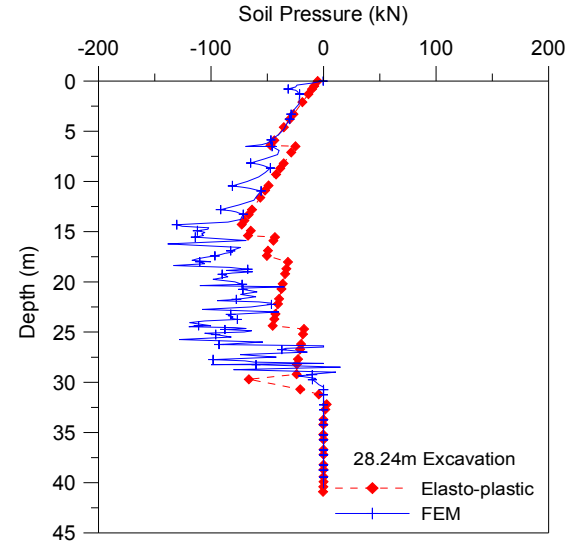

(c) $28.24 \mathrm{~m}$ Excavation

Fig. 9 Earth pressure distribution of anchored retaining wall 


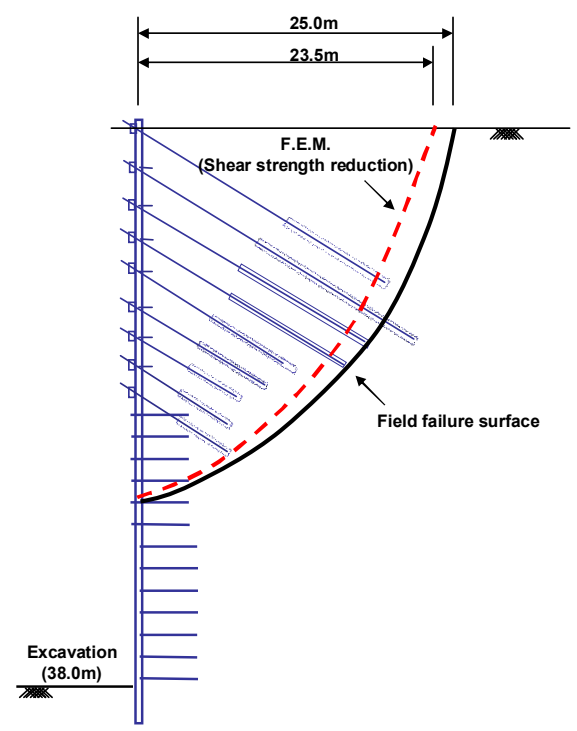

Figure 10. Comparition of failure surfaces

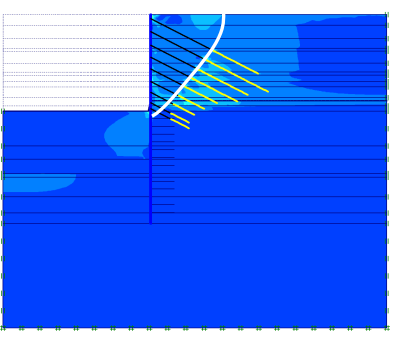

(a) $18 \mathrm{~m}$ Excavation

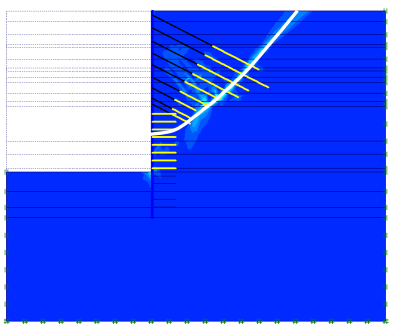

(c) $31 \mathrm{~m}$ Excavation

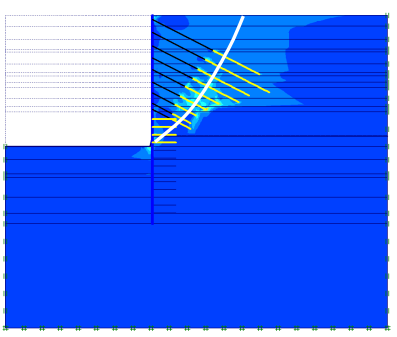

(b) $25 \mathrm{~m}$ Excavation

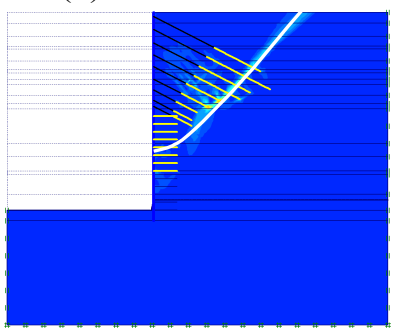

(d) $38 \mathrm{~m}$ Excavation
Figure 11 Failure surfaces at the middle stages of excavation

\section{CONCLUSIONS}

The main objective of the analysis described herein was to compare the sequential behavior of anchored retaining wall predicted by the finite element method and elasto-plastic method with the observed behavior in the field. From the comparisons, the following conclusions are drawn:

1. The finite element method utilizing the shear strength reduction technique predicted wall deflections closely compared with the measured values. However, the result of elasto-plastic method showed large discrepancy.

2. The finite element method predicted well the location of the field failure surface, which is not possible for the elasto-plastic method.

3. In overall, it was confirmed that the finite element method utilizing shear strength reduction technique can be effectively used to perform the back calculation analysis of the anchored wall structures.

\section{REFERENCES}

Briaud JL, Kim NK. (1998). Beam-column method for tieback walls. J. Geotech. Geoenviron. Eng. ASCE. 124(1). 67-79.

Cai F, Ugai K. (2000). Numerical analysis of the stability of a slope reinforced with piles. Soils Found., Jpn. Geotech. Soc. 40(1). 73-84.

Clough GW, Duncan JM. (1971). Finite element analyses of retaining wall behavior. J. Geotech. Eng. ASCE. 97(12), 1657-1673.

Clough GW, Tsui Y. (1974). Performance of tieback walls in clay. Proc J. Geotech. Div ASCE. 12(100), 1259-1273.

Donald IB, Giam SK. (1988). Application of the nodal displacement method to slope stablilty analysis. Proceedings of the $5^{\text {th }}$ Australia-New Zealand conference on geomechanics, Sydney, Australia. 456-460.

Haliburten TA. (1968) Numerical analysis of flexible retaining structure. Proc ASCE. 94(6), 1233-1251.

Hassiotis S, Chameau JL, Gunaratne M. (1997). Design method forstabilization of slopes with piles. J. Geotech. Geoenviron. Eng., ASCE. 123(4). 314-323.

Jeong, S, Seo, D. (2004). Analysis of tieback walls using proposed P-y curves for coupled soil springs. Computers and Geotechnics, Vol. 31, 443-456.

Jeong S, Kim B, Won J, Lee J. (2003). Uncoupled analysis of stabilizing piles in weathered slopes. Computer \& Geotechnics. Vol. 30. 671-682.

Korean Geotechnical Society. (2003). Korea specification for substructures (in Korean), KGS, Seoul.

Naylor DJ. (1981). Finite element and slope stability. Num Meth Geomech. Proceedings of the NATO Advanced Study Institute, Lisbon, Portugal. 229-244.

PLAXIS (2005). Program manual, version 8, PLAXIS Inc.

SUNEX (2002). Program manual, 8th edition for Ver w5.3, Geogroup Inc.

Won, J, You, G., Jeong, S., Kim, S. (2005). Coupled effects in stability analysis of pile-slope systems. Computer \& Geotechnics. Vol. 32. 304-315.

Zienkiewicz OC, Humpheson C, Lewis RW. (1975). Associated and nonassociated visco-plasticity and plasticity in soil mechanics. Geotechnique. 25(4). 671-689. 